\title{
THE INTRATRACHEAL ADMINISTRATION OF ENDOTOXIN: X. DEXAMETHASONE DOWNREGULATES NEUTROPHIL EMIGRATION AND CYTOKINE EXPRESSION IN VIVO
}

\author{
EUNHEE S. YI', DANIEL G. REMICK ${ }^{2}$, YOUNG LIM ${ }^{3}$, \\ WINSON TANG ${ }^{4}$, CHRISTINE E. NADZIENKO ${ }^{5}$, \\ ADRIANA BEDOYA ${ }^{1}$, SONGMEI YIN ${ }^{4}$, and \\ THOMAS R. ULICH ${ }^{1,4}$ \\ 'Department of Pathology \\ University of California at San Diego School of Medicine \\ San Diego, California 92103 \\ ${ }^{2}$ Department of Pathology \\ University of Michigan School of Medicine \\ Ann Arbor, Michigan 48109 \\ ${ }^{3}$ Laboratory of Molecular Immunoregulation \\ Biological Response Modifiers Program, National Cancer Institute \\ Frederick, Maryland 21702 \\ ${ }^{4}$ Amgen, Inc. \\ 1840 DeHavilland Drive \\ Thousand Oaks, California 91320 \\ ${ }^{5}$ Department of Pathology \\ University of California at Irvine School of Medicine \\ Irvine, California 92717
}

\begin{abstract}
Intratracheal instillation of endotoxin (LPS) causes acute pulmonary inflammation characterized by the accumulation of plasma proteins and leukocytes within the pulmonary airways. The synthetic glucocorticoid dexamethasone 1) inhibits the LPS-initiated vascular leak of plasma proteins into the airspace, 2) inhibits the LPS-initiated emigration of neutrophils and lymphocytes into the airspace in a dose-dependent fashion, and 3) inhibits LPS-initiated mRNA and/or bronchoalveolar lavage protein expression of cytokines (TNF, IL-1 and IL-6) and chemokines (MIP$1 \alpha$, MIP-2 and MCP-1). In conclusion, dexamethasone inhibits both the vascular and cellular aspects of acute inflammation by downregulation of a broad spectrum of inflammatory cytokines and chemokines.
\end{abstract}




\section{INTRODUCTION}

Acute inflammation is a pathophysiologic response characterized by the vascular leakage of plasma proteins into tissues as well as by the cellular emigration of neutrophils and mononuclear leukocytes from blood vessels into tissues (1). Lipopolysaccharide (LPS), the major constituent of endotoxin, is a proinflammatory component of the cell walls of gram-negative bacteria. LPS causes acute neutrophilic inflammation in the lung by upregulating proinflammatory cytokines and chemokines such as TNF (2-4), IL-1 $(2,4,5)$, CINC (6-7), and MIP-2 (7) as well as the endothelial adhesion molecule E-selectin that is a crucial molecule for neutrophilic emigration from postcapillary venules (8).

The purpose of the present study is to further characterize the model of intratracheal LPS-initiated acute inflammation by reporting: 1) The kinetics of LPS-initiated plasma protein exudation, free elastase activity, and elastase inhibitory capacity in BAL fluid; 2) The antiinflammatory effect of dexamethasone on the vascular and cellular aspects of LPS-initiated acute inflammation; 3) The downregulatory effects of dexamethasone on LPS-initiated expression of endogenous inflammatory cytokines and chemokines.

\section{MATERIALS AND METHODS}

Male Lewis rats, viral antibody free, weighing approximately $225 \mathrm{gm}$ and anesthesized with ether, were instilled intratracheally (i.t.) with LPS (Salmonella typhosa, Sigma Chem. Co., St. Louis, Missouri) or pyrogen-free saline in a volume of $0.5 \mathrm{ml}$ as previously described (2). At various time points after i.t. instillation of 10 or $100 \mu \mathrm{g}$ of LPS, bronchoalveolar lavage (BAL) was performed as previously described (2). The cell pellet from centrifuged BAL fluid was used to obtain the absolute leukocyte count and the supernatant was used for measurement of total protein, free elastase activity, elastase inhibitory capacity, and cytokine levels. Cytocentrifuge preparations stained by the Wrights-Giemsa method were used for leukocyte differentials. The antiinflammatory effect of dexamethasone was studied by the intratracheal coinstillation of LPS and dexamethasone (ElkinsSinn, Cherry Hill, New Jersey). Statistical analysis to compare the absolute numbers of neutrophils in BAL fluid in the dexamethasone plus LPS-injected rats as compared to LPS alone-injected rats was by the two-tailed t-test for unpaired data and the results were expressed as the mean plus-orminus one standard deviation.

The total protein content in BAL fluid was measured by the Lowry method (9). Protein gel electrophoresis of BAL fluid was performed to characterize the protein composition of edema fluid (10). Free elastase activity in lung lavage fluid was measured using synthetic succinyl-trialaninenitro anilide (SLAPN) as a substrate (11). Total elastase inhibitory capacity was determined by the ability of BAL fluid to inhibit elastase (10). Bioassays for TNF (WEHI 164, subclone 13) and IL-6 (B9 bioassay) were performed as previously described (12-13).

Northern blot detection of IL- $1 \beta$ and IL- 6 steady-state mRNA levels was performed as previously described $(2,7,14)$. RNase protection assay for MIP- $1 \alpha$ was performed using GAPDH as 
a loading control. Reverse transcriptase polymerase chain reaction (RT-PCR) was performed with total RNA from the rat lung extracted with a modified guanidium method (15). RT-PCR was performed with the following primers obtained from rat cDNA: (TNF $\alpha 5^{\prime} 5866$ GCA TGG ATC TCA AAG ACA ACC AAC/6233 GA ACA CCC ATT CCC TTC ACA GAG 3'; MCP-1 5' 29 CCTCCACCACTATGCAGGTC/506 GCATCACATTCCAAATCACACTAG 3'; MIP-2 5' 27 GCCAGCTCCTCAATG/304 CTTGCCTTTGTTCAG $3^{\prime}$ ). Beta-actin primer (Clontech, Palo Alto, California) served as a control. PCR was performed through 30 cycles of denaturation at $94^{\circ} \mathrm{C}$ for 1 minute, oligonucleotide annealing at $55^{\circ} \mathrm{C}$ for $1 \mathrm{~min}$ and extension at $72^{\circ} \mathrm{C}$ for 2 minutes. Reaction products were visualized by electrophoreses in $1.0 \%$ agarose gel containing ethidium bromide.

\section{RESULTS}

Kinetics of LPS-Initiated PMN Emigration, Protein Exudation, Free Elastase Activity, and the Elastase Inhibitory Capacity in BAL Fluid. PMN emigration into BAL fluid began at 1 hour and peaked at 12 hours. The PMN number in BAL fluid returned towards control values by 48 hours (Fig. 1). Total protein exudation in BAL fluid paralleled PMN emigration (Fig. 1). Protein gel electrophoresis showed a progressive accumulation of proteins in BAL fluid that exhibited the same electrophoretic mobility as the proteins in rat serum (Fig. 2).

Elastase inhibitory capacity (EIC) in BAL fluid gradually increased and peaked at 12-24 hours after i.t. instillation of LPS (Fig. 3). EIC paralleled the development of edema. No free elastase activity was measured at any time point (data not shown), suggesting that endogenous elastase inhibitors are efficient in neutralizing elastase.

Dexamethasone Inhibits Acute Inflammation. Dexamethasone inhibited LPS-initiated acute pulmonary inflammation at six hours in a dose-dependent manner (Table I). Intratracheal coinjection with LPS $(100 \mu \mathrm{g})$ and dexamethasone at doses of $0.01 \mathrm{mg}(n=6), 0.1 \mathrm{mg}(n=6)$ and $1.0 \mathrm{mg}(n=6)$ inhibited acute inflammation by $47 \%, 67 \%$, and $79 \%$, respectively as compared to intratracheal LPS injection alone $(n=18)(p<0.002,0.001$, and 0.0001 , respectively, Table I). The absolute numbers of neutrophils and lymphocytes serially enumerated at 2, 4, 6, 8, 12, 24 and 48 hours were also markedly decreased by dexamethasone $(500 \mu \mathrm{g})$ as compared to LPS (100 $\mu \mathrm{g})$ alone (Fig. 4). Dexamethasone inhibited protein exudation into BAL fluid as shown by protein gel electrophoresis (Fig. 2).

Dexamethasone Inhibits LPS-Initiated Expression of Cytokines and Chemokines. TNF mRNA expression was not detected constitutively in whole lung by RT-PCR. After i.t. LPS challenge, TNF mRNA was upregulated between 2 and 6 hours (Fig. 5). Dexamethasone $(500 \mu \mathrm{g})$ blocked the induction of TNF mRNA (Fig. 5). Intratracheal coinstillation of LPS and dexamethasone also 


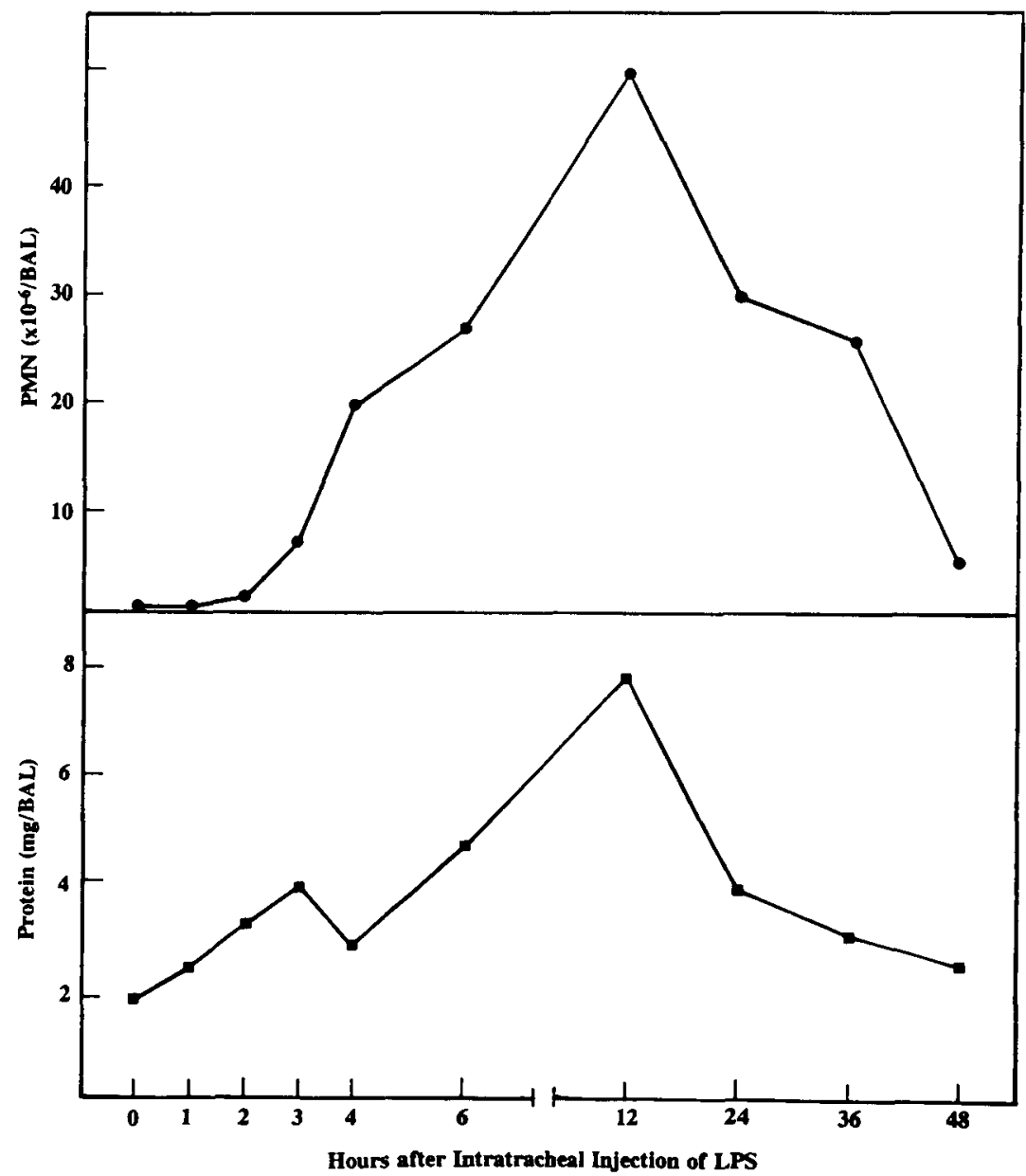

Fig. 1. A single intratracheal injection of LPS $(100 \mu \mathrm{g})$ causes accumulation of PMNs in BAL fluid peaking at 12 hours. The kinetics of protein exudation in edema fluid parallels the kinetics of neutrophilic emigration.

decreased LPS-induced mRNA expression of the cytokines IL-1 $\beta$ and IL-6 at 6 hours (Fig. 6).

The bioactivity of the cytokines TNF and IL- 6 in BAL fluid was measured at $0,2,4,6,8,12,24$ and 48 hours $(n=3$ at each time point) after the i.t. injection of LPS or after i.t. coinstillation of LPS and dexamethasone $(500 \mu \mathrm{g})$. LPS-induced TNF in BAL fluid peaked at 6 hours and returned to near pre- 


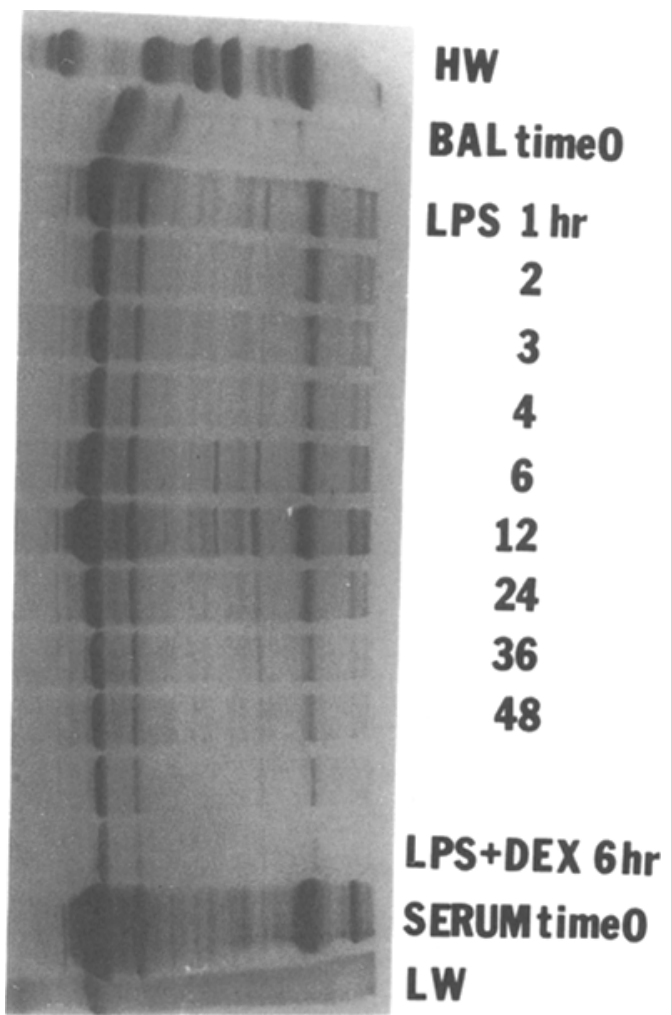

Fig. 2. The composition of LPS-induced edema protein in BAL fluid is shown by protein gel electrophoresis to be similar to the composition of plasma protein. Dexamethasone coinjected intratracheally with LPS substantially blocks plasma protein exudation.

challenge level by 12 hours (Fig. 4). Dexamethasone prevented the LPS-induced elevation of TNF protein in BAL fluid by $86 \%(p<0.002$, Fig. 4). IL-6 bioactivity also peaked at 6 hours (Fig. 4). Dexamethasone decreased the LPSinduced IL- 6 level at 6 hours in BAL fluid by $65 \%(p<0.007$, Fig. 4$)$.

In addition to its downregulatory effect on cytokines, dexamethasone inhibited the expression of chemokines. Dexamethasone mildly to moderately decreased LPS-induced MIP-2 mRNA expression. MIP-2 was not constitutively expressed but was detected in abundance at 2,4 , and 6 hours after i.t. injection of LPS (Fig. 5). Dexamethasone almost completely inhibited LPS-induced MCP1 m-RNA expression. MCP-1 was not constitutively detected and became maximally expressed between 2 and 8 hours after i.t. LPS (Fig. 5). LPS-induced mRNA expression of MIP- $1 \alpha$ was also decreased by dexamethasone (Fig. 7). 


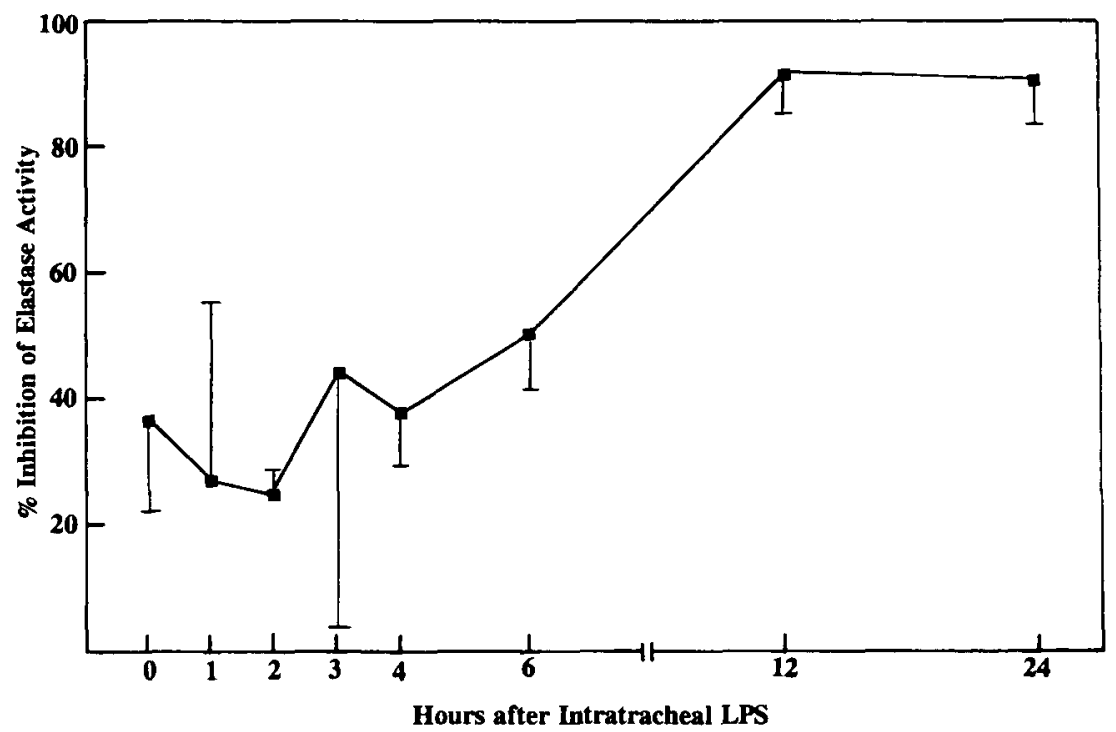

Fig. 3. An increase in the anti-elastase activity in BAL fluid accompanies the exudation of plasma proteins into BAL fluid, consistent with the fact that plasma proteins in edema fluid are a main source of elastase inhibitors.

\section{DISCUSSION}

Intratracheal instillation of LPS causes acute inflammation characterized by the accumulation of neutrophils and edema fluid within the intra-alveolar space. The kinetics of neutrophil emigration into the bronchoalveolar space parallels the exudation of serum proteins into BAL fluid, consistent with observations of previous investigators that LPS-induced exudation of edema fluid is neutrophil dependent (16-18). Protein gel electrophoresis of BAL fluid and serum supports

Table I. Dexamethasone Inhibits Intratracheal LPS-Initiated Acute Pulmonary Inflammation

\begin{tabular}{llrcc}
\hline Experimental Groups & $\mathrm{n}$ & PMN $\times 10^{-6}$ & $\%$ Inhibition & p-Value \\
\hline LPS + saline & 6 & $11.2 \pm 2.5$ & & \\
LPS + Dex $(.01 \mathrm{mg})$ & 6 & $6.0 \pm 2.2$ & $47 \%$ & 0.002 \\
LPS + saline & 6 & $13.1 \pm 3.4$ & & \\
LPS + Dex $(0.1 \mathrm{mg})$ & 6 & $4.3 \pm 1.3$ & $67 \%$ & 0.001 \\
LPS + saline & 6 & $14.2 \pm 3.1$ & & \\
LPS + Dex $(1.0 \mathrm{mg})$ & 6 & $3.0 \pm 1.0$ & $79 \%$ & 0.0001 \\
\hline
\end{tabular}



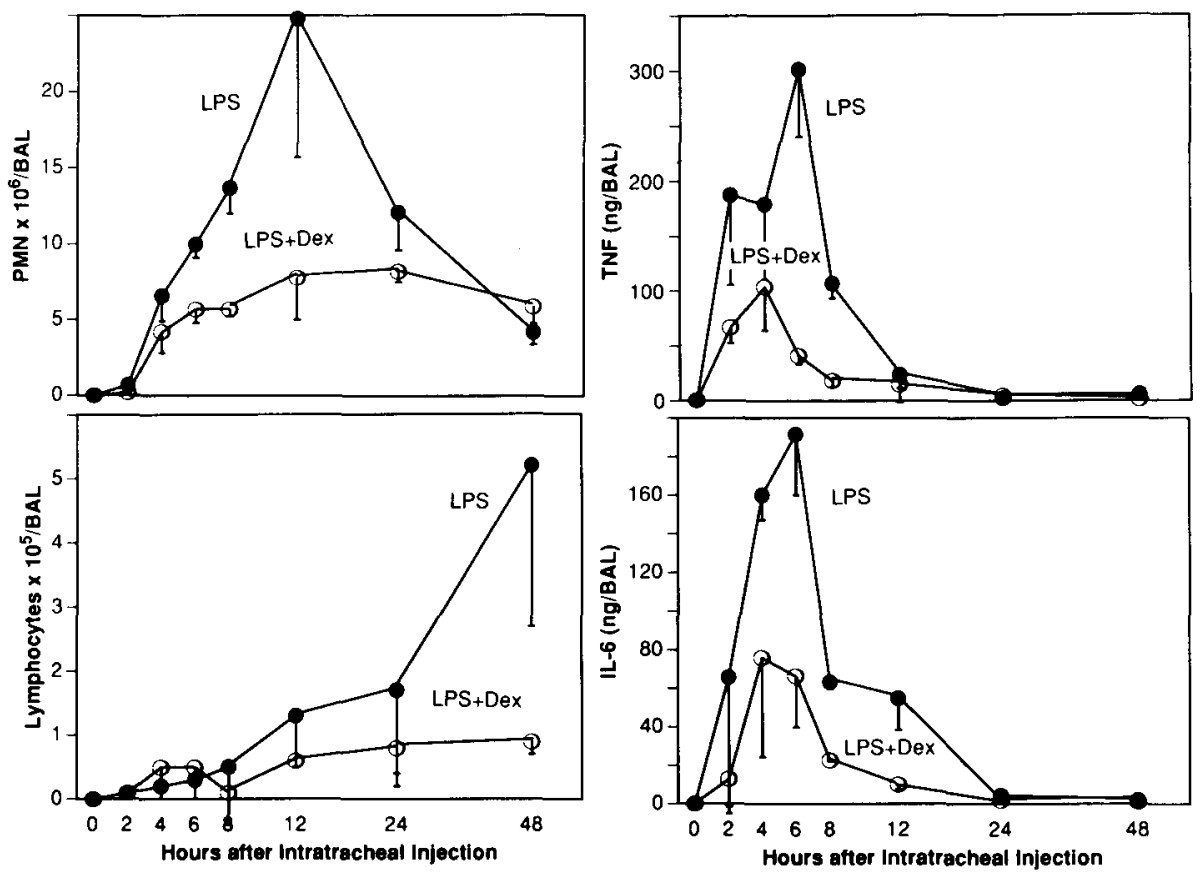

Fig. 4. Dexamethasone decreases the LPS-initiated emigration of neutrophils and lymphocytes into BAL fluid. LPS-initiated TNF and IL- 6 protein expression in BAL fluid peaks at 6 hours, preceding the peak of protein exudation and neutrophil emigration at 12 hours. TNF and IL- 6 expression are inhibited by dexamethasone.

the concept that intraalveolar edema is the result of vascular leakage of circulating proteins. Anti-elastase activity in BAL fluid as assessed by elastase inhibitory capacity rose in concert with the accumulation of plasma proteins, consistent with the fact that serum proteins in edema fluid are the major source of elastase inhibitors. The anti-elastase activity of BAL fluid is extremely efficient since no free elastase is detectable in BAL fluid at any time point after the intratracheal administration of LPS.

The expression of the proinflammatory cytokine TNF in BAL fluid preceded the peak of intraalveolar neutrophil accumulation. LPS also caused mRNA expression of the C-X-C chemokines MIP-2 and MIP- $1 \alpha$ and the C-C chemokine MCP-1. The expression of these chemokines also preceded the peak of PMN influx into the lung. MIP-2 has previously been reported by Huang et al to be upregulated in LPS-induced pneumonitis (7). MCP-1 is a monocyte chemotactic and activating factor in vitro that may contribute to the influx of monocytes in vivo (19-20). Enhanced production of MCP-1 has been implicated in 


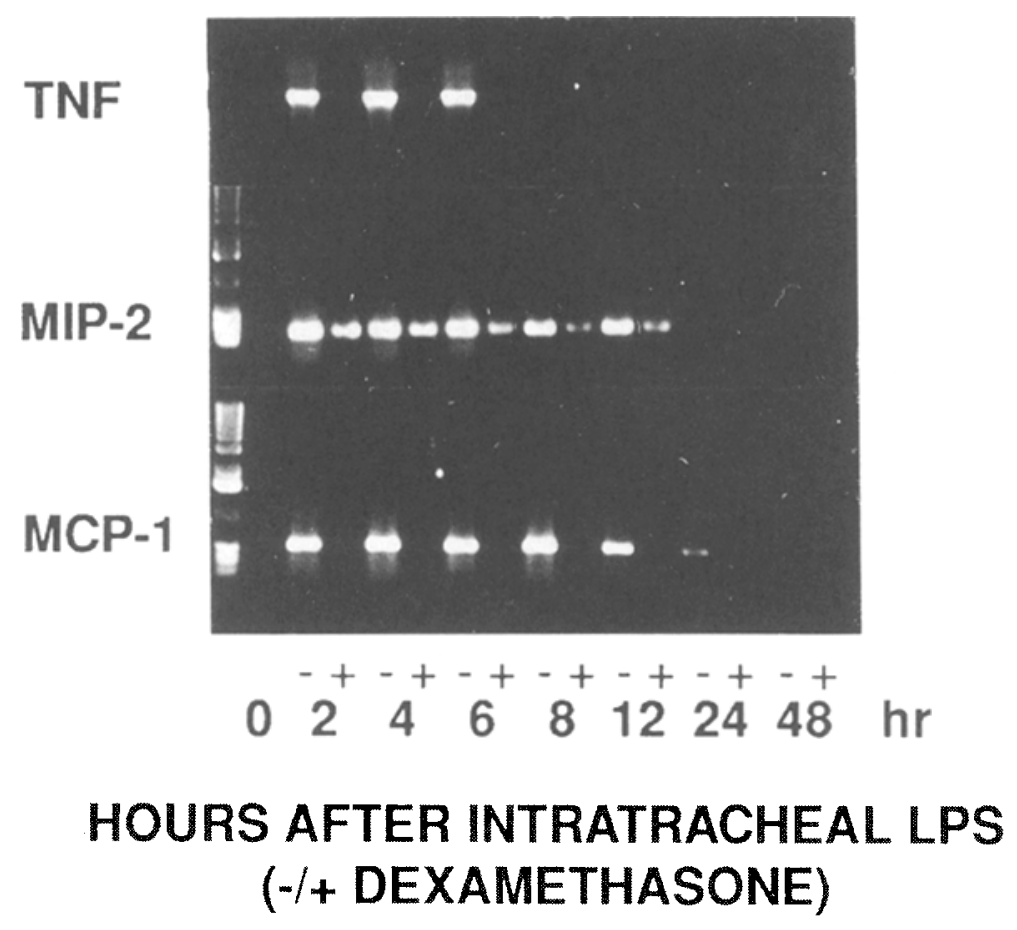

Fig. 5. Dexamethasone downregulates LPS-initiated TNF $\alpha$, MIP-2 and MCP-1 mRNA in whole lung RNA as shown by RT-PCR assay.

the pathogenesis of immune complex-mediated acute inflammatory lung injury (21) as well as other inflammatory diseases such as rheumatoid arthritis (22).

Acute inflammation is accompanied by the production of endogenous glucocorticoids. Dexamethasone, a pharmacologic glucocorticoid, strongly inhibited PMN emigration and was the most potent single anti-inflammatory agent tested in our laboratory to date in LPS-induced acute pneumonitis. The dexamethasone-induced decrease in edema protein was probably, in part, indirectly caused by the inhibition of neutrophil emigration. Downregulation of TNF, IL-1, MIP-1 $\alpha$, MIP-2, and MCP-1 expression by dexamethasone suggested that the anti-inflammatory effect of dexamethasone was exerted by the suppression of multiple proinflammatory cytokines, and chemokines. The dexamethasonerelated decrease in LPS-induced IL-6 expression was most likely attributable in part to the downregulation of TNF which normally contributes to IL-6 upregulation.

In conclusion, LPS-induced acute inflammation in vivo is orchestrated by the interactions of multiple proinflammatory cytokines, chemokines and endo- 

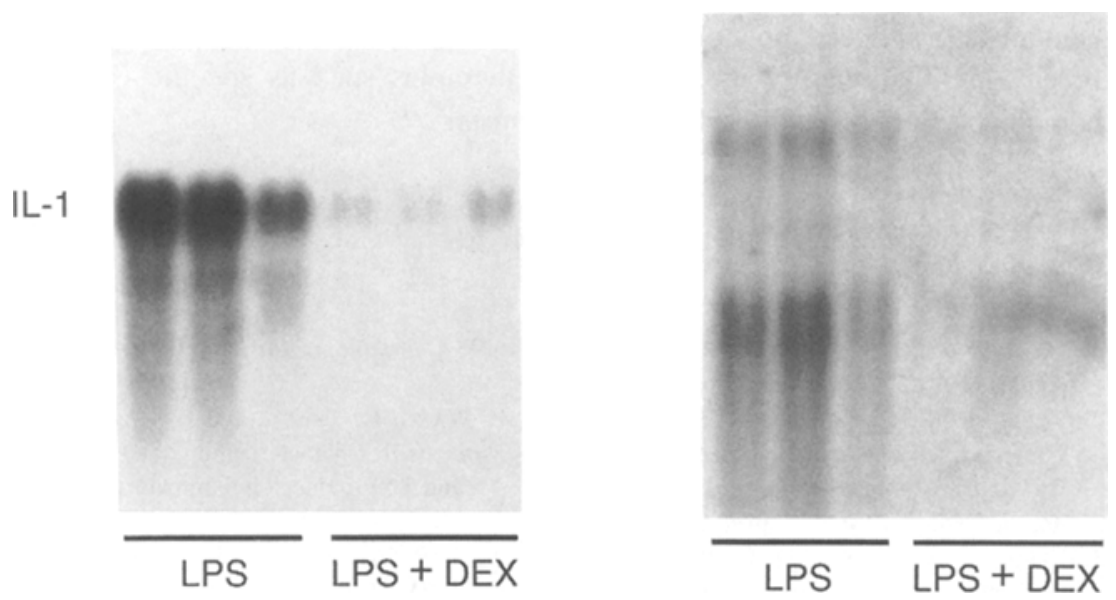

\section{SIX HOURS AFTER INTRATRACHEAL INJECTION}

Fig. 6. Dexamethasone downregulates LPS-initiated IL-1 $\beta$ and IL-6 mRNA expression in whole lung RNA at 6 hours as shown by Northern blots.

thelial adhesion molecules (2-8). The anti-inflammatory effect of dexamethasone in LPS-initiated acute inflammation appears to be mediated by the downregulation of a broad spectrum of proinflammatory molecules, suggesting an explanation for the observation that dexamethasone is a more potent antiinflammatory agent than previously tested therapeutics in this model that target a single proinflammatory molecule. The efficacy of dexamethasone as an antiinflammatory

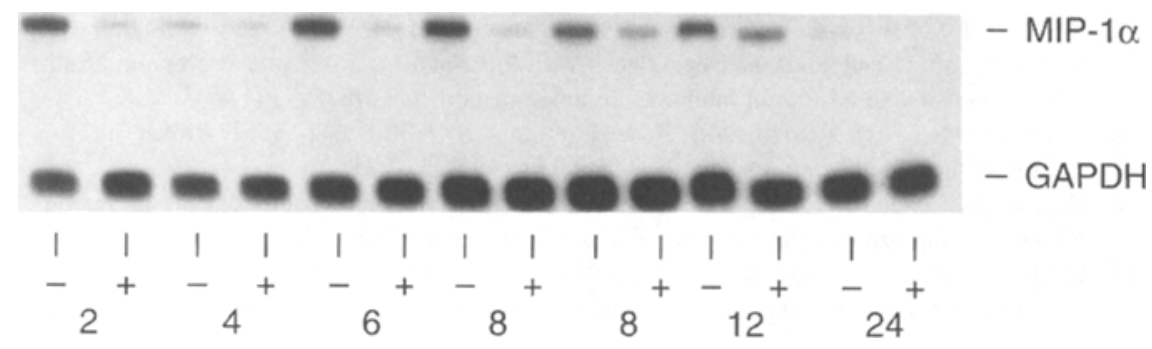

HOURS AFTER INTRATRACHEAL INJECTION $(-1+$ DEXAMETHASONE)

Fig. 7. Dexamethasone downregulates LPS-initiated MIP-1 $\alpha$ mRNA expression as shown by RNase protection assay. 
agent in LPS-induced pneumonitis can serve as a reference for the potential clinical antiinflammatory utility of novel therapies such as specific cytokine, chemokine, and adhesion molecule antagonists.

\section{REFERENCES}

1. Cotran, R. S., V. Kumar, and S. L. Robbins. 1989. Pathologic Basis of Diseases. Philadelphia, PA, W. B. Saunders, pp. 40-63.

2. Ulich, T. R., L. R. Watson, S. Yin, K. Guo, P. Wang, H. Thang, and J. del Castillo. The intratracheal administration of endotoxin and cytokines: $I$. Characterization of LPS-induced IL- 1 and TNF mRNA expression and the LPS-, IL-1-, and TNF-induced inflammatory infiltrate. Am. J. Pathol. 138:1485-1496.

3. Ulich, T. R., S. Yin, D. G. Remick, D. Russel, S. P. Eisenberg, and T. Kohno. 1993. Intratracheal administration of endotoxin and cytokines: IV. The soluble tumor necrosis factor receptor type I inhibits acute inflammation. Am. J. Pathol. 142:1335-1338.

4. UliCH, T. R., E. S. YI, S. YIN, C. SMITH, and D. G. RemICK. 1994. Intratracheal administration of endotoxin and cytokines: VII. The soluble interleukin-1 receptor and the soluble tumor necrosis factor receptor II (p80) inhibit acute inflammation. Clin. Immunol. Immunopathol. 72:137-140.

5. Ulich, T. R., S. Yin, K. Guo, J. del Castrllo, S. P. Eisenberg, and R. C. Thompson. 1991. The intratracheal administration of endotoxin and cytokines: III. The interleukin-1 (IL1) receptor antagonist inhibits endotoxin- and IL-1-induced acute inflammation. Am. J. Pathol. 138:521-524.

6. Ulich, T. R., S. C. Howard, D. G. Remick, A. Wittwer, E. S. Yi, S. Yin, K. Guo, J. K. WELPLY, and J. H. Williams. Intratracheal administration of endotoxin and cytokines: VI, LPS induces CINC chemotactic peptide expression and antiserum to CINC inhibits acute inflammation. Am. J. Physiol. (Lung Cell Mol Physiol), in press.

7. Huang, S., J. D. Paulauskis, J. J. Godleski, L. Kobzik. 1992. Expression of macrophage inflammatory protein-2 and KC mRNA in pulmonary inflammation. Am. J. Pathol 141:981988.

8. Ulich, T. R., S. C. Howard, D. G. Remick, E. S. Yi, T. Collins, K. Guo, S. Yin, J. L. Keene, J. J. Schmuke, C. N. Steinger, J. K. Welply, and J. H. Williams. 1994. Intratracheal administration of endotoxin and cytokines: VIII. LPS induces E-selectin expression. Anti-E selectin and soluble E-selectin inhibit acute inflammation. Infl 18:389-394.

9. Lowry, O. H., N. J. Rosebrough, A. L. Farr, and R. J. Randall. 1951. Protein measurement with the folin phenol reagent. J. Biol. Chem. 193:265-275.

10. Nadzrejko, C., and J. Chen. 1994. Increased elastase inhibitory capacity of lung lavage fluid following acute ozone exposure: role of serum transudation. Inhal. Tox. 6:57-65.

11. Fujita, J., N. L. Nelson, D. M. Daughton, C. A. Dobry, J. R. Spurzen, S. Irino, S. RENNARD. 1990. Evaluation of elastase and antielastase balance in patient with chronic bronchitis and pulmonary emphysema. Am. Rev. Respir. Dis. 142:57-62.

12. Ulich, T. R., B. Irwin, D. G. Remick, and G. N. Davastellis. 1990. Endotoxin-induced cytokine gene expression in vivo: II. Regulation of TNF and IL-1 expression and suppression. Am. J. Pathol. 137:1137-1145.

13. Ulich, T. R., K. Guo, D. G. Remick, J. Del Castillo, S. Yin. 1991. Endotoxin-induced cytokine gene expression in vivo. III. IL-6 mRNA and serum protein expression and the in vivo hematologic effects of IL-6. J. Immunol. 146:2316-2323. 
14. Northermann, W., T. A. Bracial, N. Hatton, F. Lee, and G. H. Fey. 1990. Structure of the rat IL-6 gene and its expression in macrophage-derived cells J. Biol. Chem. 264:160-172.

15. Chirgwin, J., A. Przbyla, and R. MacDonald. 1979. Isolation of biologically active ribonucleic acid from sources enriched in ribonuclease. Biochemistry 18:5294-5299.

16. YI, E. S., T. R. ULiCH. Endotoxin, interleukin-1, and tumor necrosis factor cause neutrophildependent microvascular leakage in postcapillary venules. Am. J. Pathol. 1992, 140:659-663.

17. Hocking, D. C., P. G. Phillips, T. J. Ferro, and A. Johnson. 1990. Mechanisms of pulmonary edema induced by TNF. Circ. Res. 67:68-77.

18. Stephens, K. E., A. Ishizaka, Z. H. Wu, J. W. Larrick, T. A. Raffin. 1988. Granulocyte depletion prevents TNF-mediated acute lung injury in guinea pigs. Am. Rev. Respir. Dis. 138:1300-1307.

19. Matsushima, K., C. G. Larsen, G. C. DuBois, J. J. Oppenheim. Purification and characterization of a novel monocyte chemotactic and activating factor produced by a human myelomonocytic cell line. J Exp. Med. 169:1484-1490.

20. Jiang, Y., D. I. Beller, G. Frendl, D. T. Graves. 1992. Monocyte chemoattractant protein1 regulates adhesion molecule expression and cytokine production in human monocytes. $J$ Immunol. 148:2423-2428.

21. Brieland, J. K., M. L. Jones, S. J. Clarke, J. B. Baker, J. S. Warren, J. C. Fantone. 1992. Effect of acute inflammatory lung injury on the expression of monocyte chemoattractant protein-1 (MCP-1) in rat pulmonary alveolar macrophages. Am. J. Respir. Cell. Mol. Biol. 7:134-139.

22. Косh, A. E., S. L. Kunkel, L. A. Harlow, B. Johnson, H. L. Evanoff, G. K. Haines, M. D. Burdick, R. M. Pope, R. M. Strieter. 1992. Enhanced production of monocyte chemoattractant protein-1 in rheumatoid arthritis. J. Clin. Invest. 90:772-779. 